\title{
Removal of Dyes from Wastewater by Ceramic Membrane
}

\author{
RAMY MOHAMED JEBIR AL-ALAWY ${ }^{1}$, BAKER M. ABOD ${ }^{1}$, FIRAS HASHIM KAMAR ${ }^{1}$, AURELIA CRISTINA NECHIFOR ${ }^{2 *}$ \\ ${ }^{1}$ Institute of Technology- Baghdad, Middle Technical University, Iraq \\ 2 University Politehnica of Bucharest, Department of Analytical Chemistry and Environmental Engineering, 1-7 Gheorghe Polizu \\ Str., 011061, Bucharest, Romania
}

\begin{abstract}
The currentstudy aimed to investigate the elimination of dyes from sewerage, using microfiltration membrane mechanism. Three dyes were applied, acid yellow-23, disperse blue -79 and acid orange -7. Experiments were performed with feed concentration (40-120) ppm, feed flow rate (25-65) l/h and time (0.25-1.5) h. The membrane used ceramic membrane, constructed as a candle. It was discovered that water flow diminishes with an elevation in running time, feeding oil concentration and enhancing with elevation in the feed flow rate. In addition, it was determined that the elimination (rejection) rate of dyes enhances with elevation in the flow rate, and the elimination (rejection) rate diminishes as time passes. In cross flow microfiltration, the rejection concentration (concentrate) goes up as time passes, with high feed concentration and flow rate. It was also discovered that the modal infusion concentration declines with high feed concentration and working time. In addition, it was found that product rate goes down as time passes and with high feed concentration. Increasing feed concentration of dyes was associated with an increase in the concentration of rejecting solution. The highest elimination of disperse blue -79, Acid Yellow- 23 and acid orange -7, are $97 \%, 96.4 \%$ and $95.8 \%$, respectively. The maximum recovery percentage of disperse blue - 79, acid yellow- 23 and acid orange -7are $57.7 \%, 58.5 \%$ and $59 \%$ respectively.
\end{abstract}

Keywords: dyes; microfiltration membrane; ceramic membrane; fouling modeling.

In diversified industrial operations, large amounts of dyes are utilized; specifically in the fabric manufacturing's for coloring cotton [1,2]. The fabric manufacturing is specified, by using a large volume of water. Indeed, by considering both composition and volume, the sewerage from fabric coloring manufacturing is classified as the highest pollutant, among all manufacturing districts, and is categorized as non- toxic, in spite the fact that it harbors an inconstant chemical constitution of organic composites like surfactants, synthetic dyes, nitrols, starch, derivatives cellulose, emulsifiers, carbamide, different organic materials and cellulose $[3,4]$. Dye has high stability upon exposure to heat and light. In addition, more attention should be paid to the use of automations, which can supply more stability in the atmosphere facing oxidants, bleaches and sunlight, [5-7]. The most traditional and common management procedure for these kinds of drainage are established, using chlorination, activated sludge, and chemical precipitation, membrane process and adsorption of activated carbon [8-10]. Lately, numerous determinants have resulted in the invention of membrane separation machinery. Membrane procedure is mostly selected in water management processes, as these implementations fulfill big eliminations of components like inorganic ions, organic carbon, and dissolved solids. Membrane mechanism, including NF (nan filtration), RO (reverse osmosis), UF (ultrafiltration) and MF (microfiltration) are applied worldwide to ultra-pure and potable water manufacturing, desalination of seawater, also chemical process separations. As a pretreatment for RO procedures and NF, the UF and MF have been applied [11]. Microfiltration is a filtration procedure that operates at a physical filtering separate procedure. It is mostly applied to elimination of, Giardia, the solids in suspension Cryptosporidium and minimization of impurity and cloudiness. Microfiltration procedure needs small transmembrane pressure $\{<30 \mathrm{psi}\}$ to function; it is too applied as a prerequisite in electrodialysis, desalination procedures, including RO and NF. MF membranes can function in either dead-end filtration or cross-flow separation. In cross- flow separation only a section of feed flow is treating and the rest of water passes across the membrane, in not treated form. However, all the feed water is treated, in dead-end separation process. The MF membrane is made up of diverse substances, for instance, polypropylene, polysulfone, Polyvinyldifluoride (PVDF), carbon, $\mathrm{ZrO}_{2}$, and Polyethersulfone (PES) [12]. In this search, the efficiency of separation processes for membrane (Microfiltration) for treatment of dyes in drainage water, and reduction of dyes' content in high permeate and permeate flow, were investigated. In addition, the effects of working determinants, including the feed flow rate, dyes concentration, time and different types of dyes in a MF section were examined. Straightforward filtration replicas have also been applied to assist in the analysis of the MF membrane-fouling procedure.

\section{Experimantal part}

Modeling of fouling

The permeation flow of particle-free water through an uncluttered membrane can be explained, using Darcy's law as:

$$
\boldsymbol{J}=\frac{\Delta \boldsymbol{p}}{\mu \boldsymbol{R}_{m}}
$$

where $\Delta p(p a)$ the Trans membrane, $J\left(\mathrm{~m}^{3} \mathrm{~m}^{-2} \mathrm{~s}^{-1}\right)$ is the permeation flux, pressure (TMP), $R_{\mathrm{m}}\left(\mathrm{m}^{-1}\right)$ the hydraulic resistance of the clean membrane (or clean membrane resistance) and $\mu(\mathrm{kg} / \mathrm{m} . \mathrm{s})$ the absolute viscosity of the water. The permeation flux will constantly be lower than that defined in the eq.1, in case of suspension filtration. Low flux is a consequence of the high membrane resistance against the permeating flow, occurred from particle sedimentation on or in membrane or membrane fouling. Membranes contamination processes commonly

\footnotetext{
* email: aureliacristinanechifor@gmail.com
} 
involve cake formation, pore blocking and concentration polarization. For MF, Pollution may be due to polarization of concentration not be significant, because of the massive volume of the pieces sieved [13].

Therefore, the permeation flux across a MF section for treatment of suspensions, like oily drainage water, can be defined by altering the equation (1), as:

$$
\boldsymbol{J}=\frac{\Delta \boldsymbol{p}}{\mu\left(\boldsymbol{R}_{p}+\boldsymbol{R}_{m}+\boldsymbol{R}_{c}\right)}
$$

where $R_{(}\left(\mathrm{m}^{-1}\right)$ is the resistance because to cake formation and $R_{\mathrm{r}}\left(\mathrm{m}^{-1}\right)$ the resistance because of pore blocking. For MF at a consistent TMP, the primary permeates flux $J_{0}$ will principally rely on $R_{\mathrm{m}}$, because $R_{\mathrm{c}}$ and $R_{\mathrm{p}}$ are primarilyzero. In the course of M'F action, cake formation and pore blocking will cause $R$ and $R$ to enhance, and alter the relative significance of $R_{\mathrm{m}}, R_{\mathrm{f}}$ and $R_{\mathrm{p}}$ in the equation (2), and the MF procedure It can be moved from a membrane resistance to a cake resistance process or a pore blocking resistance. Accordingly, usually four fouling processes can be seen for porous membranes [13].

\section{Standard blocking model}

In the standard blocking model, the piece dimension is smaller than the pore dimension; therefore, the pieces can pass the majority of the pores, place on the pore walls, and consequently minimize the pore volume. The decline in pore volume is also relative to the permeate volume.

\section{Complete blocking model}

Complete blocking model presumes that pieces get to the membrane and block the membrane pores in a way that the pieces do not overlap with the other. The obstructed area is relative to the permeate volume.

\section{The cake filtration model}

The cake filtration model is applied to describe the immense pieces, which cannot pass the majority of pores, and therefore, accumulation creates a cake on the membrane exterior.

\section{Intermediate blocking model}

In the intermediate blocking model, the total of surface or blocked pores is also accepted to be relative to the permeate volume, how ever it is less limited in a way that not each piece naturally obstructs the pores and pieces may locate on other pieces.

For MF at Fixed membrane pressure, the permeation fluxes, following each of these circumstances can be defined as in equations and according to their previous sequence, as follows:

$$
\begin{aligned}
& J=J_{0}\left(1+\frac{1}{2} K_{s}\left(A J_{0}\right)^{0.5} t\right)^{-2} \\
& J=J_{0} \exp \left(-k_{b} t\right) \\
& J=J_{0}\left(1+2 K_{c}\left(A J_{0}\right)^{2} t\right)^{-0.5} \\
& J=J_{0}\left(1+K_{i} A J_{0} t\right)^{-1}
\end{aligned}
$$

where $J$ relies on the Trans membrane pressure, membrane viscosity and resistance of the filtrate are expressed as $J_{0}=\Delta P / \Delta \mu R_{m}$. The diverse $K$ terms show mass transfer coefficients for the associated filtration laws [14].

In the circumstance of consistent pressure filtration, the term $(A J)$ is consistent and the filtration laws in the previous sequence can be interpreted to: 


\section{Experimental procedure}

In order to prepare feed solution, 10 liter of running water was mixed with dyes in the QVF glass vessels. As a stable wastewater needed during the experiment, only small amounts of dyes were added to the water. In order for the wastewater to fill the entire system pipes, the valve that was outsourcing was left open. To remove dyes from dyes - water (wastewater), the wastewater feed was coming from the vessel feed, using a centrifugal pump to enter the membrane (Ceramic filter). The volume of permeate in the course of the interval was examined and documented, after the collection of the permeate (filtered water). Figure 1 presents the schematic diagram of MF process. By means of a UV spectrophotometer, the dyes concentrations in feed and penetrate solutions were examined.

For water treatment, the standard cross flow system model uses the plug flow theory. In a plug flow system, the feed volume enters the system. A permeate is defined as a certain portion of the feed, which enters through the membrane. The feed is slowly concentrated and moves from the system with a higher concentration. In the plug flow, if the size of elements is too limited, the concentrate recirculation will be used in order to accomplish an adequate high system recovery. In this process, with inner concentrate recirculation, the concentrate flowing out of the MF membranes, will be managed back to the feed vessel of the unit and combined with the feed flow. After documenting the data, the solution (staying in the feed vessel), was removed, using a drain valve. The full systems were rinsed by moderately hot water for $20 \mathrm{~min}$, and subsequently the water was removed. In addition, detergent solution was allowed to circulate through the equipment for further $20 \mathrm{~min}$, and then drained.

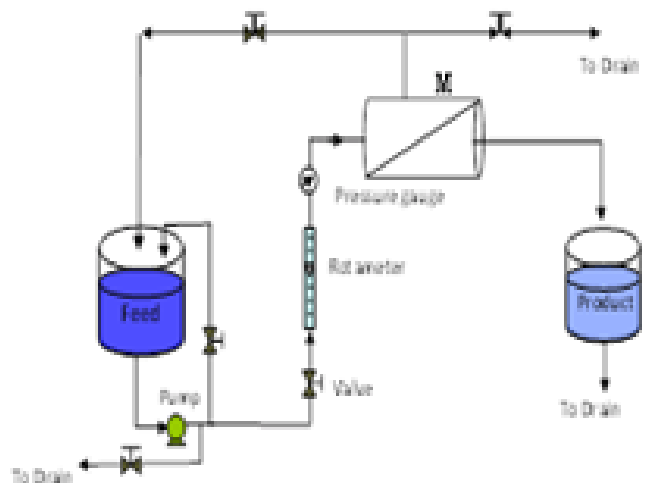

Fig. 1. Schematic Diagram of Microfiltration Process

\section{Results and discussions}

Influence of feed concentration

As the Concentrate feeding dye increased, it looked that the water stream across the membrane also decreased, and additionally the product rate diminished as shown in figure 2 . Based on the equation 11, recovery is directly related to the product rate. As the product rate goes up, the recovery will also increase for all specifications, examined in the currentstudy and inversely. Figure 3 shows the impact of augmenting feed concentration as a function of the product concentration. The result of the present work seems to be in a good agreement with those observed by [16] for the effect of different dye concentration.

\section{Influence of time}

Figure 4 demonstrates the impact of time on the recovery and the figure 5 indicates that the rejection percentage decreased with time; because of the accumulation of fouling on the exterior of the membrane. The product rate for membrane section diminishes with passing of time while operating. The product percentage

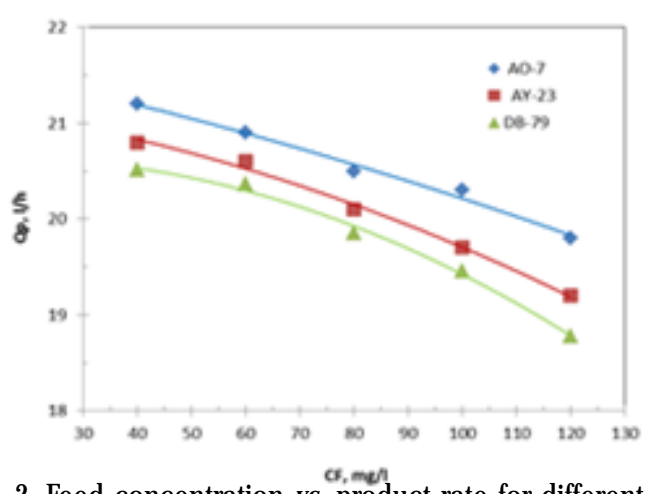

Fig. 2. Feed concentration vs. product rate for different dyes $\left(Q_{F}=45 \mathrm{~L} / \mathrm{h}, \mathrm{T}=20 \pm 2^{\circ} \mathrm{C}\right.$, time $\left.=1 \mathrm{~h}\right)$

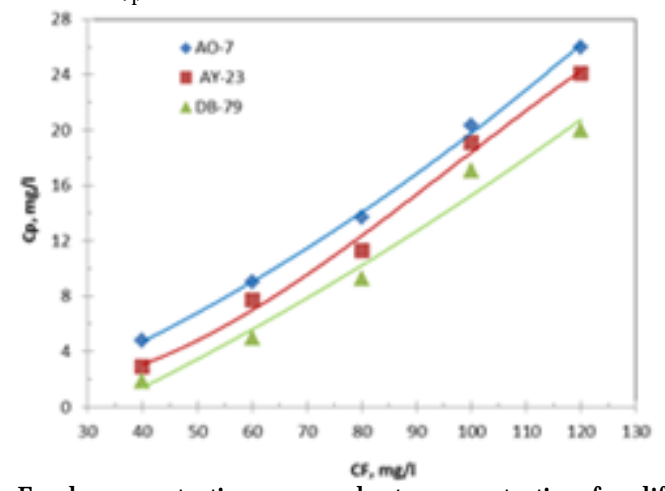

Fig. 3. Feed concentration vs. product concentration for different dyes $\left(Q_{F}=45 \mathrm{~L} / \mathrm{h}, T=20 \pm 2{ }^{\circ} \mathrm{C}\right.$, time $\left.=1 \mathrm{~h}\right)$

of a membrane system diminishes as fouling happens, due to the retardation of the back diffusion of the dye in bulk solution by the membrane surface, in order to create concentration polarization at the exterior of the membrane. A decrease in the product rate is caused by Increase in polarization of concentration, suggesting the decrease in product rate as a function of the increase in time, while operating, as demonstrated in figure 6 . An elevation in fouling of membrane is due to the increase in time. This suggests the dye concentration will be increased as time passes while operating, as shown in figure 7 . The result of the present work is an agreement with [4].

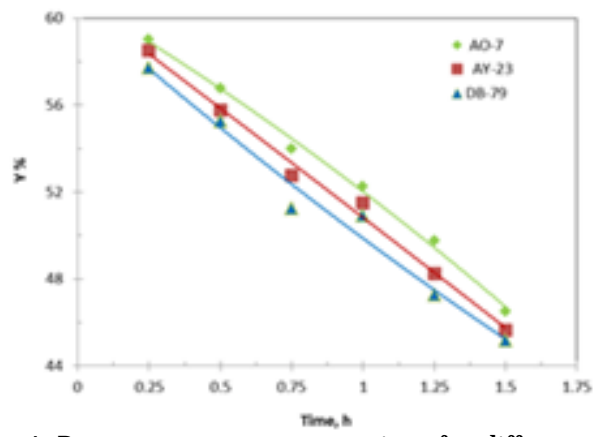

Fig. 4. Recovery percentage vs. time for different dyes $\left(Q_{F}=45 \mathrm{~L} / \mathrm{h}, \mathrm{C}_{\mathrm{F}}=80 \mathrm{mg} / \mathrm{L}, \mathrm{T}=20 \pm 2{ }^{\circ} \mathrm{C}\right)$

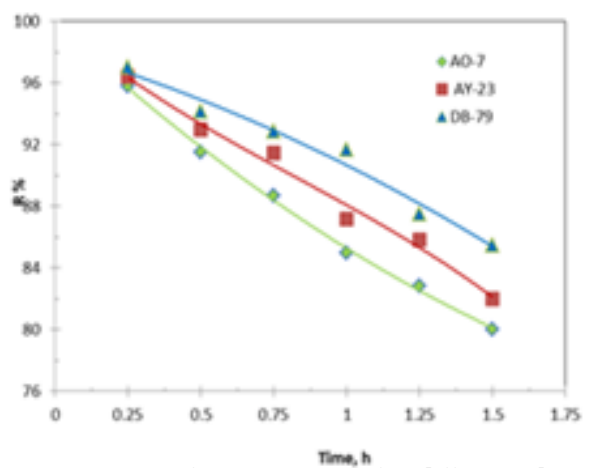

Fig. 5. Recovery factor vs. time, for different dyes $\left(Q_{F}=45 \mathrm{~L} / \mathrm{h}, \mathrm{C}_{\mathrm{F}}=80 \mathrm{mg} / \mathrm{L}, \mathrm{T}=20 \pm 2^{\circ} \mathrm{C}\right)$ 


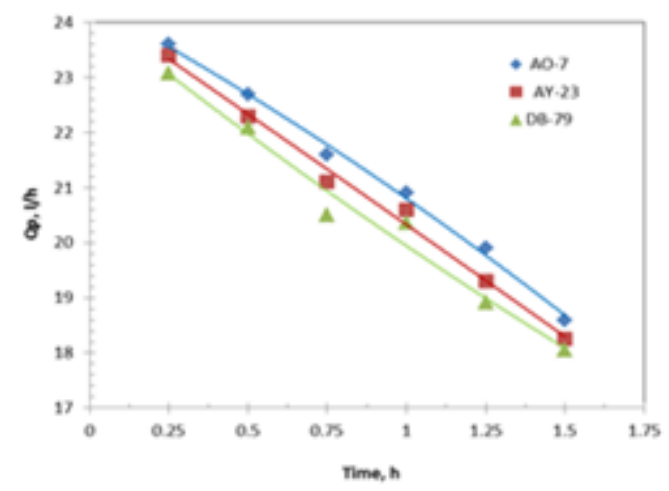

Fig. 6. Product rate vs. time for different dyes $\left(Q_{F}=45 \mathrm{~L} / \mathrm{h}, \mathrm{T}=20 \pm 2{ }^{\circ} \mathrm{C}, \mathrm{C}_{\mathrm{F}}=80 \mathrm{mg} / \mathrm{L}\right)$

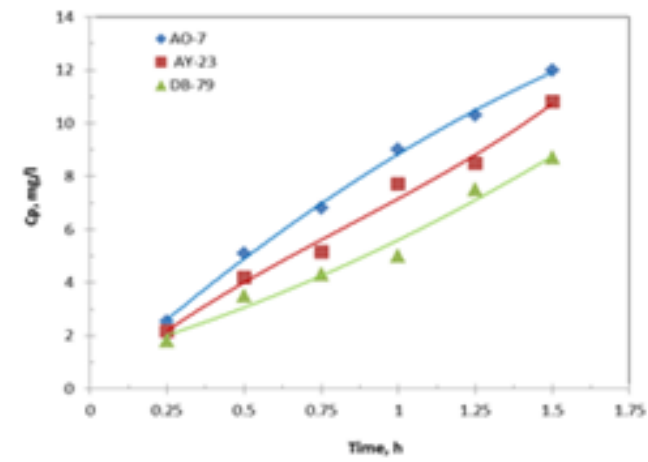

Fig. 7. Product concentration vs. time for different dyes $\left(Q_{F}=45 \mathrm{~L} / \mathrm{h}, \mathrm{T}=20 \pm 2{ }^{\circ} \mathrm{C}, \mathrm{C}_{\mathrm{F}}=80 \mathrm{mg} / \mathrm{L}\right)$

\section{Influence of feed rate}

In membrane, flow rate is a crucial working specification. The cake formation and/or concentration polarization are reduced by a high flow rate. The transfer of heat to and dispersing heat far from the membrane exterior characterize the rate of growth of fouling, the dispersing of heat is related to the degree of turbulence and the rate of convection to the membrane is related to the permeate flux. Based on this information we see, an elevation in the

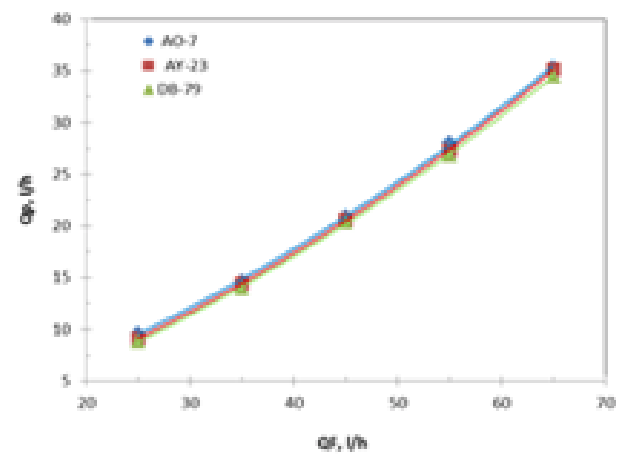

Fig. 8. Product rate vs. feed rate for different dyes (time $1 \mathrm{~h}$, $\left.\mathrm{T}=20 \pm 2{ }^{\circ} \mathrm{C}, \mathrm{C}_{\mathrm{F}}=80 \mathrm{mg} / \mathrm{L}\right)$

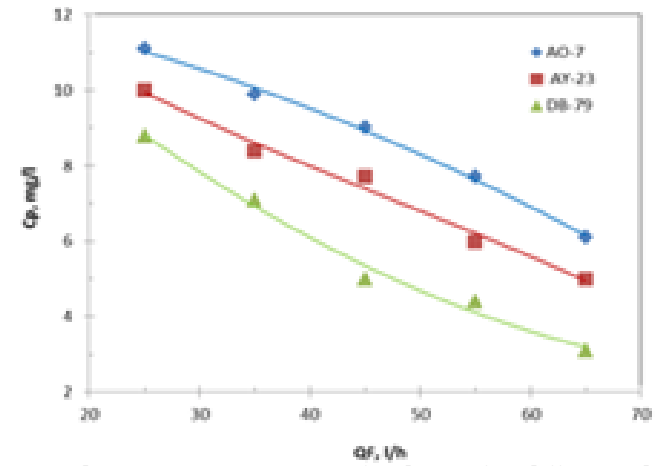

Fig. 9. Product concentration vs. feed rate for different dyes (time $1 \mathrm{~h}, \mathrm{~T}=20 \pm 2{ }^{\circ} \mathrm{C}, \mathrm{C}_{\mathrm{F}}=80 \mathrm{mg} / \mathrm{L}$ ) feed flow rate caused the flux to increase. A direct decrease in product concentration occurs due to an increase in the feed flow rate [11]. This is shown in figures 8 and 9.

\section{Experimental work with Modeling of Fouling}

We can calculate modeling of fouling by the equations $7,8,9$, and 10 , and compare with experimental work vs. time. In intermediate pore blocking model and complete pore blocking model occasions, the models demonstrate a logical consistency and linear correlations with experimental data, as shown in figures 10, 11 and 12 in different dyes. These results correspond with the results of the researcher $[17,18]$.

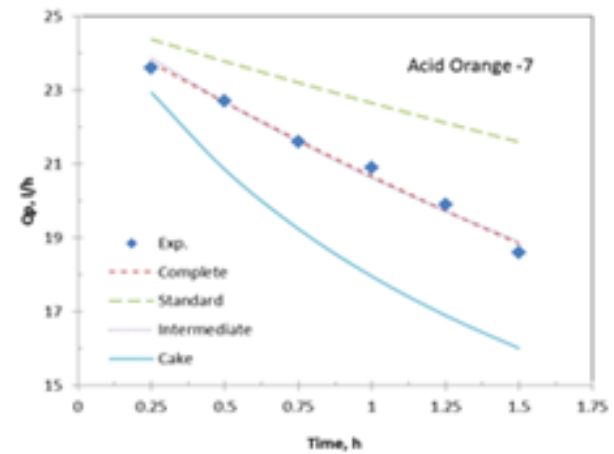

Fig. 10. Experimental data for Acid Orange -7 dye with comparison of filtration model prediction

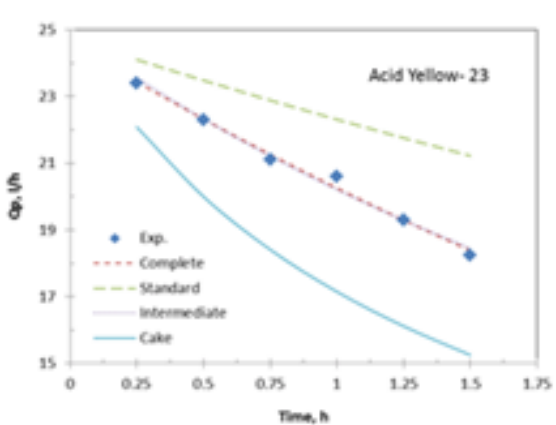

Fig. 11. Experimental data for Acid Yellow- 23 dye with comparison of filtration model prediction

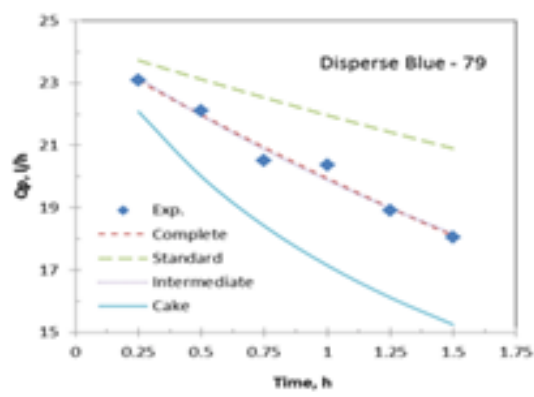

Fig. 12. Experimental data for Disperse Blue - 79 dye with comparison of filtration model prediction

\section{Conclusions}

Microfiltration (MF) is a chemical separation process can be used to remove dyes from sewerage water. From experimental data we can conclude that amount of flux for acid orange - 7 dye more than disperse blue - 79 and acid yellow - 23 dyes, but the rejection percentage for Acid Orange -7 dye is less than the rejection percentage for disperse blue - 79 and acid yellow- 23 dyes. The maximum recovery percentage for acid orange -7, acid yellow- 23 and disperse blue - 79 are $59 \%, 58.5 \%$, and $57.7 \%$, respectively. The maximum rejection for acid orange -7 , acid yellow- 23 and disperse blue - 79 are 95.8\%, 96.4\%, 
and $97 \%$, respectively. Experimental data in this study were in good consistency with the intermediate pore blocking model and complete pore blocking model.

\section{References}

1.PETRINIC, I., RAJ ANDERSEN, N.P., SOSTAR-TURK, S., LE MORECHAL, A.M., The removal of reactive dye printing compounds using nanofiltration, Dyes and pigments, 74, no. 3, 2007, p. 515.

2.KAMAR, F.H, NIAMAT, F.E., FAISAL, A.A.H., MOHAMMED, A.A., NECHIFOR, A.C., NECHIFOR, G., Use of Artificial Neural Network for Modeling and Prediction of Reactive Red Dye Removal from Wastewater Using Banana Peels Bio-sorbent, Rev. Chim.(Bucharest), 69, no.8, 2018, p. 1919.

3.VELMUURUGAN, P., RATHINA, K. V., DHINAKARAN, G., Dye removal from aqueous solution using low costadsorbent, International J ournal of Environmental Sciences, 1, no. 7, 2011, p. 1492.

4.AL - NAKIB, N. M., Reverse Osmosis Polyamide Membrane for the Removal of Blue and Yellow Dye from Waste Water, Iraqi Journal of Chemical and Petroleum Engineering, 14, no. 2, 2013, p. 49.

5.SELIM, K.A., YOUSSEF, M.A., HASSAN, M.S., ABD EL-RAHIEM, F.H., Removal of dyes from aqueous solutions using surface modified bentonite and glauconi minerals, J ournal of ORE Dressing, 15, no. 29, 2013, p. 21

6.BOUYAKOUB, A.Z., KACHA, S., LARTIGES, B., BELLEBIA, S., DERRICHE Z., Treatment of reactive dye solutions by physicochemical combined process, J ournal of Desalination and Water Treatment, 12, no.1-2, 2002, p. 202.

7.ABBAS, S.H., KAMAR, F.H, HOSSIEN, Y.K., Adsorption of Methyl Violet 2B Dye from Aqueous Solutions onto Waste of Banana Peel using Fixed-Bed Column, International J ournal of Civil Engineering and Technology (IJCIET), 9, no. 9, 2018, p. 2095.

8.ALLEN, W., PRESCOTT, W.B., DERBY, R.E., GARLAND, C.E., PERET, J. M., SALTZMAN, M., Determination of color water and wastewater by means of ADMI $28^{\text {th }}$ color values, Proceedings of the 28th Industrial Waste Conference, Purdue Univ., Eng. Ext. Ser., 142, 1973, p. 661. 9.ALBANIS, T.A., HELA, D.G. SAKALLARIDES, T.M., DANIS, T.G., Removal of Dyes from Aqueous Solution by Adsorption on Mixture of Fly Ash and Soil in Batch and Column Techniques, Global Nest; the Int. J., 2, no. 3, 2000, p. 237.

10.AL-ASEERI, M., BU-ALI, Q., HAJI, S., AL-BASTAKI, N., Removal of Acid Red and sodium chloride mixtures from aqueous solutions using nanofiltration, Desalination, 206, no. 1-3, 2007, p. 407.

11.CHERYAN, M., Ultrafiltration and Microfiltration Handbook, Lancaster, United States: Technomic Publishing Company, 1998, p. 71.

12.PETER, A. WILLIAMS, Handbook of Industrial Water Soluble Polymers, by Blackwell Publishing Ltd, 2007.

13.BAl, R.B., LEOW, H.F., Microfiltration of activated sludge wastewater - the effect of system operation parameters, Sep. and Purif. Technol., 29, no. 2, 2002, p. 189.

14.NANDI, B.K., MOPARTHI, A., UPPALURI, R., PURKAIT, M.K., "Treatment of oily wastewater using low cost ceramic membrane: Comparative assessment of pore blocking and artificial neural network models", Chemical Engineering Research and Design, 88, 7, 2010, p. 881.

15.PENG, H., TREMBLAY, A.Y., Membrane regeneration and filtration modeling in treating oily wastewaters, Journal of Membrane Science, 324, no. 1-2, 2008, p. 59.

16.GHOLAMI, M., NASSERI, S., ALIZADEHFARD, M., MESDAGHINIA, A., Textile dye Removal by Membrane Technology and Biological Oxidation, Water Qual. Res. J. Cananda, 38, no. 2, 2003, p. 379.

17.MAKKI, H.F., AL-ALAWY, A.F., AL-HASSANI, M.H., RASHAD, Z.W., Membranes Separation Process for Oily Wastewater Treatment, J ournal of Engineering, 17, no. 2, 2011, p. 15.

18.POPA, G.A., NECHIFOR, G., ENACHE (POPA), D.F., TANCZOS, S.-K., CIOCANEA,A., Polymeric membranes prepared with surfactants used for ultrafiltration of aqueous solutions of food dye, Studia UBB Chemia, 4, Tom I, 2017, p. 47.

Manuscript received: 16.11 .2018 